\title{
MAPPING VELOCITY OF THE POTSDAM GLACIER, EAST ANTARCTICA USING LANDSAT-8 DATA
}

\author{
S. D. Jawak ${ }^{1}$, M. Joshi' ${ }^{2,3,}$, A. J. Luis ${ }^{4}$, P. H. Pandit ${ }^{5}$, S. Kumar ${ }^{6}$, S. F. Wankhede ${ }^{4}$, Anirudh T. Somadas ${ }^{7}$
}

${ }^{1}$ Svalbard Integrated Arctic Earth Observing System (SIOS), SIOS Knowledge Centre, University Centre in Svalbard (UNIS), P.O. Box 156, N-9171, Longyearbyen, Svalbard, Norway; shridhar.jawak@gmail.com

${ }^{2}$ Department of Geoinformatics, Mangalore University, Mangalore, Karnataka-574199, India

${ }^{3}$ Divecha Centre for Climate Change, Indian Institute of Science, Bangalore, Karnataka - 560012; mansijoshi692@gmail.com ${ }^{4}$ Earth System Science Organization - National Centre for Polar and Ocean Research, Ministry of Earth Sciences, Government of India, Headland Sada, Vasco-da -Gama, Goa 403804, India; alvluis@ ncaor.gov.in, swankhede436@gmail.com

${ }^{5}$ National Bureau of Soil Survey and Land Use planning (NBSS \& LUP) - Indian Agriculture Research Institute (IARI), New Delhi, India; sh.prashantpandit@gmail.com

${ }^{6}$ Centre for Land Resource Management, Central University of Jharkhand, Ranchi - 835205, India; shubh30195@ gmail.com ${ }^{7}$ University of Twente, Faculty ITC, P. O. Box 217, 7500 AE Enschede, Netherlands; a.tharaventhedathsomadas@ student.utwente.nl

KEY WORDS: Glacier velocity, image matching, pixel tracking, Landsat-8 OLI, Antarctic glacier

\begin{abstract}
:
Most of the glaciers have been retreating and thinning globally due to climate change. Glacier velocity is one such important parameter of glacier dynamics, which helps to understand the mass balance. The variations in velocity at different areas of the glacier can be used to identify the zones of ablation and accumulation. Zones of accumulation are identified as areas with higher velocity. This data is useful to incorporate in the glacier mass balance analysis. This study aims to derive the glacier velocity, using feature tracking technique for Potsdam glacier, east Antarctica. Feature tracking is an efficient way to derive glacier velocity, which is based on a cross-correlation algorithm that seeks offsets of the maximal correlation window on repeated satellite images. In this technique, two temporally different images are acquired for the same area and a distinct feature on both images is identified and the velocity is calculated with respect to the movement of that particular feature from one image to the other. Landsat- 8 data for the year 2016 was used to derive velocity. Finer resolution promotes better feature tracking so the panchromatic band (band 8) of Landsat-8 OLI with a resolution of $15 \mathrm{~m}$ was utilized for deriving velocity. This technique was performed using COSI-Corr module in ENVI. This tool calculates displacement between the east-west and north-south directions, and the resultant velocity is calculated using the displacement in both directions and the temporal difference of two images. The velocity map generated at a resolution of $240 \mathrm{~m}$ showed that the resultant velocity ranged between 18.60 and $285.28 \mathrm{ma}-1$. Bias and root mean square error (RMSE) have been calculated with respect to the point-by-point MEaSUREs data provided by National Snow and Ice Data Centre at 1000 $\mathrm{m}$ resolution. The RMSE was found to be $78.06 \mathrm{ma}-1$ for 2016 . The velocity for Potsdam glacier was also pictorially validated with the DGPS measurements from literature.
\end{abstract}

\section{INTRODUCTION}

Glacier ice deforms under the force of gravity and is able to slide on the ground. The resulting ice flow observed at the surface represents the mass transport between areas with predominant snow accumulation and those with prevailing mass loss by ice melt or break-off. The effects of climate warming are for instance evident in the continuous retreat of glaciers. Thus, measuring glacier flow-fields decisively contributes to understanding glaciers and related hazards (Kääb et al., 2002). Glacier velocities can be measured using different remote sensing techniques such as, Interferometric Synthetic Aperture Radar (InSAR), Differential Interferometric SAR (DInSAR), offset tracking, feature tracking with GPS, speckle tracking, feature tracking, etc. These techniques work on different time scales and have different strengths and shortcomings, and so they complement each other in glaciological studies (Heid et al., 2011), Like GPS based tracking, It is more advantageous when only small features are available for tracking in a study area because these features may not be discernible on the images. On the other hand, GPS is disadvantaged by the problem of accessibility. Remotely sensed data helps in handling the issues of inaccessibility.

Although glacier-surface velocities can be measured directly on the glacier with high accuracy at arbitrary spatial and temporal resolutions, observations over long periods involve frequent revisits of the survey points, which can only be located on the accessible parts of a glacier. Therefore, field measurements commonly result in very sparse spatial coverage. Because of the huge degree and troublesome openness of high rugged landscape, remote-sensing strategies give an effective method to gather information in disparate regions. In contrast, remote sensing-based measurements provide the opportunity to achieve large and possibly complete spatial coverage, even in very remote areas. Remotely sensed imagery can provide detailed and timely data for Earth observation across both time and space, which enhances the ability to map and monitor glacier flow on a nearly global scale (Pandit et al., 2018). Optical satellite image-based ice-velocity measurement using feature tracking is a well-established method (Jawak et al., 2018). Feature tracking involves tracking identifiable features between pairs of optical satellite images using an image-matching algorithm such as normalized cross-correlation (NCC), crosscorrelation operated in the frequency domain on orientation images (CCF-O), and co-registration of optically sensed images and correlation (COSI-Corr) (Liu et al., 2017). Cross correlation is also applied to provide in image registration in areas devoid the bedrock exposure. The use of cross-correlation software is a significant improvement over previous manually-based 
photogrammetry methods for velocity measurement, and is far more cost-effective than in situ methods in remote polar areas. Glacier displacements have been derived using optical images, radar images and using detailed DEMs treated as images. In all three cases, the purpose is to identify the same features in two images from different times so that velocity can be derived. It was found that the feature-tracking method provides an alternative to Synthetic Aperture Radar (SAR) interferometry, requiring no ground control points and enabling measurement of surface velocities in regions and over periods not covered by radar satellite missions (Copland et al., 2009). Optical images have existed for a long time as terrestrial images, aerial images and satellite images. There are many optical satellite sensors, and these have generated, and still generate, a large number of optical data with various spatial resolutions. Hence, data access is easy using optical images and many of the images are available at no cost. However, optical satellite images of glaciers can be useful only if they are obtained during cloud free daylight conditions, and this is a major limitation when using such images. Especially in maritime areas it can be difficult to obtain cloud free images, and darkness during 6 months limits the method to be used only during summer in Polar Regions (Heid et al., 2011). Moderate resolution satellite images such as Landsat, permit glacier movement to be measured on sequential images covering the same area: the velocity of floating ice can be measured quickly and relatively inexpensively by tracking crevasse patterns on shelves and ice tongues (Lucchitta et al., 1993). In this study, we have used the feature tracking method to calculate the velocity over Potsdam glacier. Feature-tracking is a method that allows the estimation of a displacement between first image called reference image and a second image or search image (Dehecq et al., 2015).

Previous studies have demonstrated the usefulness of sequential satellite Imagery for glacier velocity measurements, To date, visually based photogrammetric techniques have been widely used, consisting of co-registering two images using bedrock outcrops, selecting surface features on the ice, visually finding their location on the subsequent image, and manually or mechanically measuring their displacement. Small, sharp surface features are required for high precision when visual techniques are used, Precisions are limited by the pixel size of the image data, since the location of any extended feature in the image is referenced to a single pixel location somewhere on the feature.

The process of correlating two or more images containing the same image objects is called image matching. Besides deriving the velocity of glaciers, this method has also been used in several different fields including photogrammetry, image mosaicking, map updating, face detection, change detection, video coding, tectonics and monitoring of tumour growth in medical science. Different fields use different terms for image matching based on its purpose. Image registration, motion estimation, particle tracking and optical flow are all terms that are used, which essentially mean the same as image matching. When using image matching to derive glacier velocities, it is important that the time span between the images is long enough to detect significant displacements, but short enough so that the objects are still recognizable. The length of this time span can vary with the velocities of the glaciers, the resolution of the images, the accuracy of the matching method, the amount of surface melt and the strain rates. The longer the time span, the larger is the displacement compared to the accuracy of the match; however, the chance of having too large surface transformation to get a correct match increase (Heid et al., 2011; Scambos et al., 1992).

\section{STUDY AREA}

In this study we focus on the Potsdam glacier is located south of the Schirmacher oasis, and to the north of Wohlthat Massif. Most portion of this glacier is situated at height greater than $1000 \mathrm{~m}$ above mean sea level. The annual air temperature is below $-20^{\circ} \mathrm{C}$ (Anschütz et al., 2007).

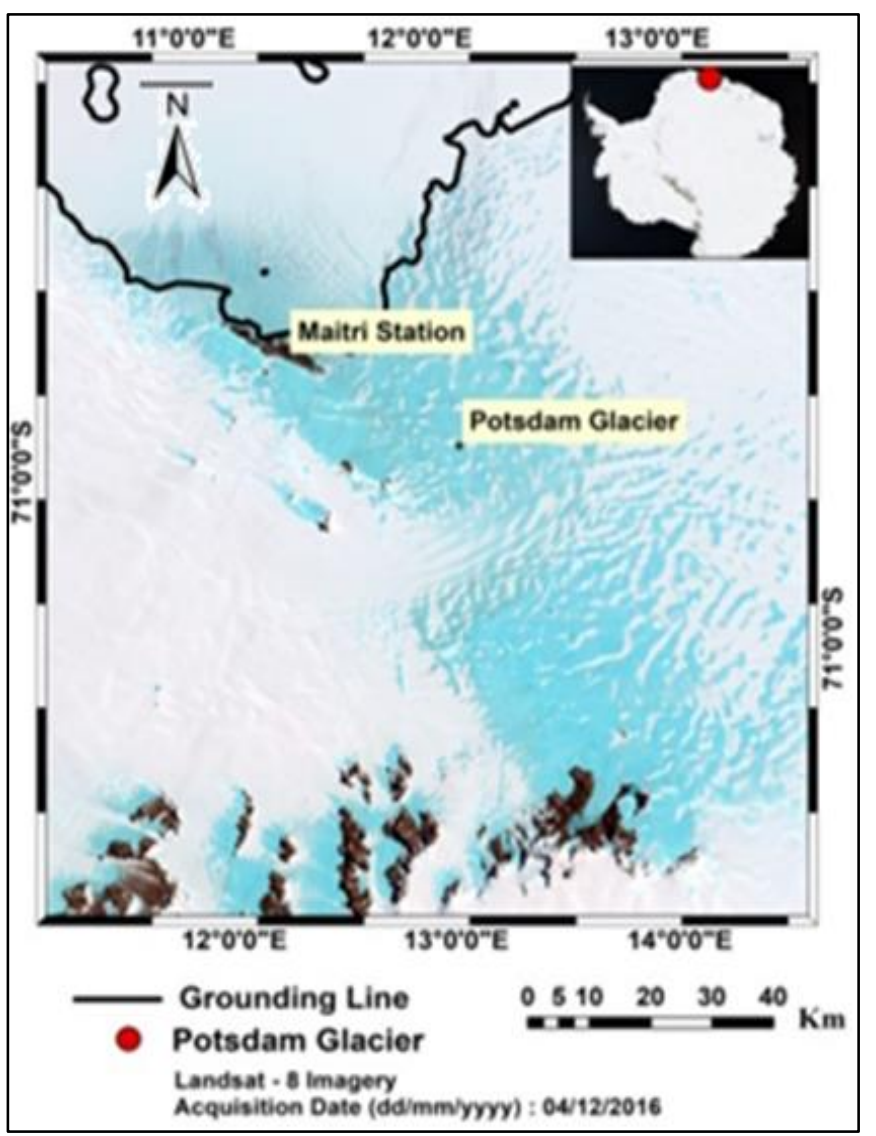

Figure 1. Study area.

The Indian Antarctic research station Maitri is located northwest, $\sim 45 \mathrm{~km}$ from this glacier. Geographically it extends from $71.25^{\circ}$ to $71^{\circ} \mathrm{S}$ and $11^{\circ}$ to $12^{\circ} \mathrm{E}$ (Figure 1). The surface elevation varies from $1350 \mathrm{~m}$ above mean sea level in southwestern part to nearly $600 \mathrm{~m}$ above sea level in the northeastern part. The thickness of the ice is nearly $>1200 \mathrm{~m}$. Accumulation dominates in this region, with the exception of small ablation areas around several Nunatak. In the most northeasterly part of this glacier, near and east of the Schirmacheroase, a large ablation area is found that reaches up to the eastern Wohlthat Massif. (Jawak et al., 2017).

\section{DATA AND MATERIALS}

Landsat-8 satellite is a part of the Earth Resources Technology Satellite (ERTS) mission, later deployed for earth observation (EO) purpose. It was launched in February 2013 with a temporal resolution of 16 days. In this study, we used multiple bands of Landsat-8. Landsat- 8 satellite imageries of different temporal resolutions were downloaded from the United State Geological Survey (USGS) website. Landsat-8 with a higher radiometric resolution is specifically useful for researchers working on cryosphere and polar remote sensing. Many glaciologists are using Landsat data for mapping glaciers, snow 
and ice. Landsat has the largest time series data available with incomparable spatial-spectral-temporal resolution.

In this study we used the panchromatic band of the Landsat- 8 satellite, it's the sharpest of all the bands, with a resolution of 15 meters. The panchromatic band is a grayscale image that covers the red, green, and blue portions of the electromagnetic spectrum.

\section{METHODOLOGY}

The workflow developed to achieve comparative classification in this study was performed as a series of steps. These steps can be broadly distributed into four major sequences as follows; (a) image rectification and restoration, (b) object-based classification, (c) pixel based classification, and (d) evaluation of accuracy. The method does not require outside data, for example, GPS measurements of ground control points (GCPs), and is exclusively based on the knowledge of the topography and on the ancillary data provided with the observing platform (positions, velocities, attitudes variations and pointing directions for spacecraft, or calibration reports for aerial photographs.) Sub-pixel change detection is then applied on the set of ortho-images produced.

\subsection{Image Rectification and Restoration}

The image matching method has been performed using Coregistration of Optically Sensed Images and Correlation (COSICorr) module that is integrated in ENVI. COSI-Corr is a highly advanced matching program developed by Leprince et al. (2007).It was originally designed for investigating tectonics, but glaciologists soon found that it was also a useful tool for deriving glacier velocities. It estimates the phase difference in the Fourier domain and does not transform the images back to the spatial domain to find the maximum of the cross correlation (Leprince et al., 2007). There are two images, the first is the reference image and the second is the search image.

The panchromatic band (band 8) of Landsat 8 OLI (Operational Land Imager) has been used to calculate velocity in this region. The reference image was acquired on 2 November 2016 and search image was recorded on 4 December 2016. The difference between the two acquisition dates of the images is 33 days. Correlation analysis is performed using window size and step size (Figure 2). The initial displacement is first estimated based on search windows, and is then refined in the sub-pixel domain. An important condition is that the range of the window size has to be large enough to capture the expected displacement. To avoid the introduction of aliasing in the ortho-rectified image, the irregular re-sampling problem is accounted for and the ortho-image is then built

Once the images are co-registered, the correlation between the two images results in two offset fields, representing the eastwest and north-south horizontal ground displacements, and a signal-to-noise ratio (SNR) field reflecting the quality of the correlation for each pixel in the images (Ruiz et al., 2015). Coregistration is the pixel-by-pixel matching and correlation is the degree of matching in image 1 and image 2. The crosscorrelation is given by the following equation.

$C_{(u, v)}=$

$$
\frac{\sum_{x, y}(f(x, y)-\bar{f}) \times((g(x+u, y+v)-\bar{g}(x+u, y+v))}{\sqrt{\sum_{x, y}((f(x, y)-\bar{f}))^{2}} \times \sqrt{\sum_{x, y}((g(x+u, y+v)-\bar{g}(x+u, y+v)))^{2}}} .
$$

Where $\mathrm{f}(\mathrm{x}, \mathrm{y})$ and $\mathrm{g}(\mathrm{x}, \mathrm{y})=$ pixel values in window $\mathrm{Q}$ and $\mathrm{Q}^{\prime}$ of image 1 and image 2; $u$ and $v=$ offsets between $Q$ and $Q^{\prime} ; \bar{f}$ and $\overline{\mathrm{g}}(\mathrm{u}, \mathrm{v})=$ average pixel values of $\mathrm{Q}$ and $\mathrm{Q}^{\prime}$

The correlation window should be large enough to accommodate largest possible displacement (Evans et al., 2000).

The resultant velocity is then calculated using:

$\mathrm{V}=\frac{\sqrt{(E-W)^{2}}+\sqrt{(N-S)^{2}}}{\text { Differenceinaquisitiondatesbetweenimagepair }}$,

where $\mathrm{E}-\mathrm{W}=$ east-west displacement, and $\mathrm{N}-\mathrm{S}=$ north-south displacement.

This is performed in ENVI using Band Math.

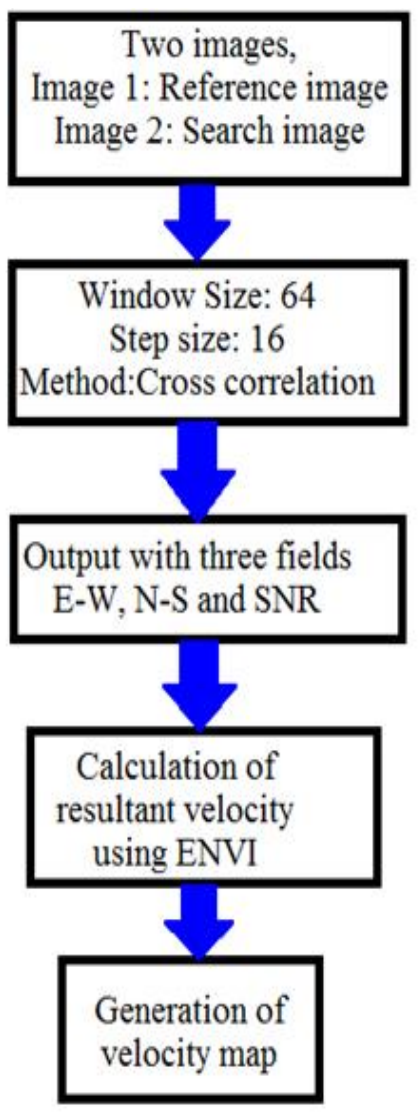

Figure 2.Methodology

\section{RESULTS AND DISCUSSION}

The resultant velocity was found to be in range from 18.6 to 285 ma-1 (Figure 3). The calculated velocity was validated with the MEaSUREs data provided by National Snow and Ice Data Centre. The bias and Root Mean Square Error (RMSE) were calculated with respect to the MEaSUREs data. Negative bias was observed in the region having high velocity, which suggests that the velocity did not show much variation with respect to the MEaSUREs dataset. The RMSE was found to be 78 ma-1 for the year 2016 . The velocity was also validated 
using DGPS measurement from the literature. The velocities in the direction of glacier flow increased from about 20-30 ma-1 at higher elevation to $70-80$ ma-1at the lower region (Anschütz et al., 2007; Reddy et al., 2008).

\section{CONCLUSION}

The velocity was calculated using Band-8, Panchromatic band from Landsat-8 OLI. It was observed that the velocity of Potsdam glacier has not varied much except for the regions of low elevation, which showed higher velocity. The higher elevation areas showed lower velocity. This was validated by GPS data through past literature. The GPS data was available only for the year of 2003-2004, however, there needs to be a continuous recording of GPS data for later years. Since, the velocity has shown variation in areas where the values are higher. Thus, a continuous monitoring of velocity over Potsdam glacier should be undertaken to document its changes over the years.

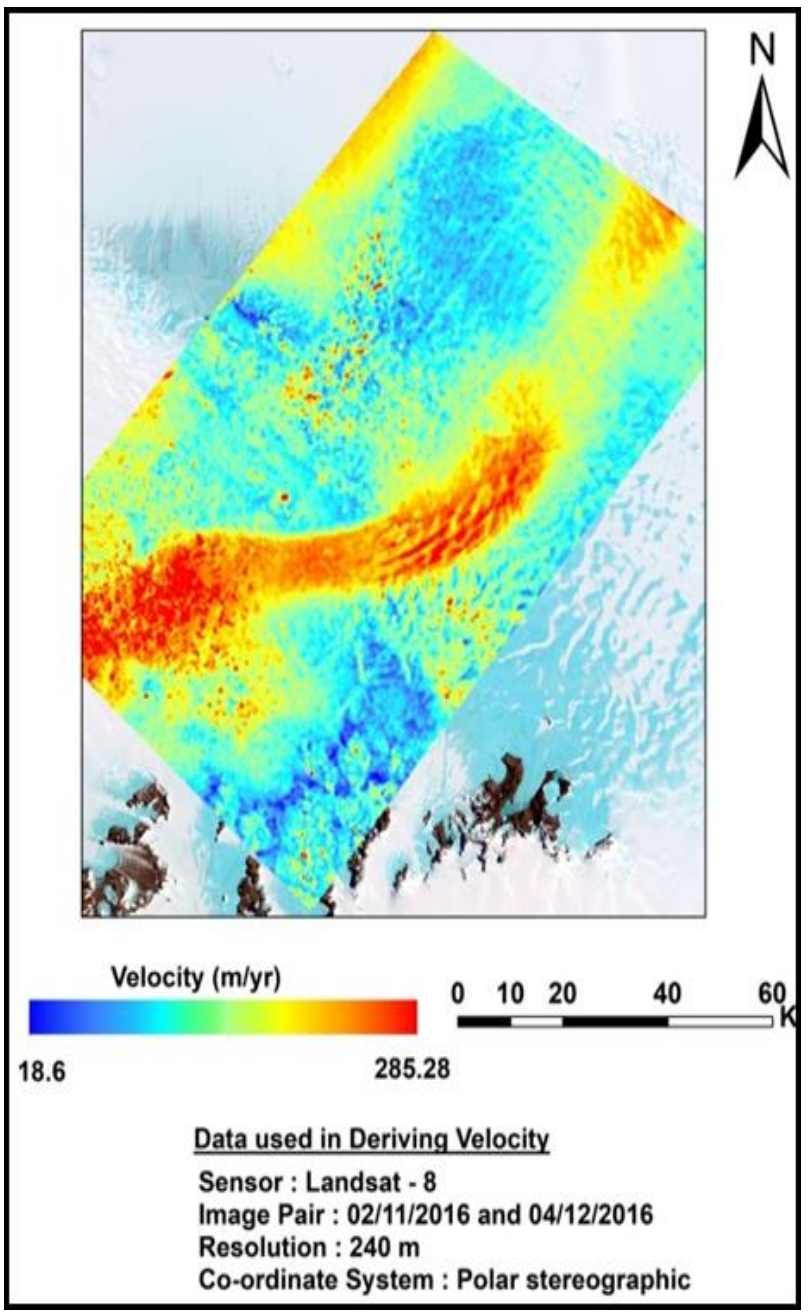

Figure 3.Derived Velocity Map

\section{ACKNOWLEDGEMENTS}

The authors would like to thank Dr. M. Ravichandran, Director, ESSO-NCAOR, for his support and motivation for this research. We also acknowledge Dr. H. Gangadhara Bhat, Chairman, Department of Marine Geology, Mangalore University, for his encouragement for this research. The entire experiment and validation was conducted at the ESSO-NCPOR. The lead author (S.D.J) has recently moved to SIOS, Longyearbyen, Norway.

\section{REFERENCES}

Anschütz, H., Eisen, O., Oerter, H., Steinhage, D., \& Scheinert, M., 2007. Investigating small-scale variations of the recent accumulation rate in coastal Dronning Maud Land, East Antarctica. In: Annals of Glaciology, 46, 14-21. DOI: 10.3189/172756407782871756.

Copland, L., Pope, S., Bishop, M. P., Shroder, J. F., Clendon, P., Bush, A., Owen, L. A., 2009. Glacier velocities across the central Karakoram. In: Annals of Glaciology, 50(52), 41-49.

Dehecq, A., Gourmelen, N., \& Trouvé, E., 2015. Deriving large-scale glacier velocities from a complete satellite archive: Application to the Pamir-Karakoram-Himalaya. In: Remote Sensing of Environment, 162, 55-66.

Evans, A. N., 2000. Glacier surface motion computation from digital image sequences. In: IEEE Transactions on Geoscience and Remote Sensing, 38(2), 1064-1072. DOI: $10.1109 / 36.841985$.

Heid, T., 2011. Deriving glacier surface velocities from repeat optical images. (Doctoral Dissertation, University of Oslo).

Jawak, S. D., Pandit, P. H., Luis, A. J., Malik, K., \& Sinha, V. S. P., 2017. Derivation of velocity of the Potsdam glacier, east antarctica using SAR interferometry. In: Proceedings of the 38th Asian Conference on Remote Sensing-Space Applications: Touching Human Lives, ACRS 2017, New Delhi, India.

Jawak, S. D., Upadhya, A., Pandit, P. H., and Luis, A. J., 2018. Changes in velocity of fisher glacier, east Antarctica using pixel tracking method, In: Archives of Photogrammetry, Remote Sensing and Spatial Information Sciences, XLII-5, 537-541. DOI : https://doi.org/10.5194/isprs-archives-XLII-5-537-2018

Jawak, S. D., Kumar, S., Luis, A. J., Bartanwala, M., Tummala, S., \& Pandey, A. C., 2018. Evaluation of Geospatial Tools for Generating Accurate Glacier Velocity Maps from Optical Remote Sensing Data. In: Multidisciplinary Digital Publishing Institute Proceedings (Vol. 2, No. 7, p. 341).

Kääb, A., 2002. Monitoring high-mountain terrain deformation from repeated air-and spaceborne optical data: examples using digital aerial imagery and ASTER data. In: ISPRS Journal of Photogrammetry and remote sensing, 57(1-2), 39-52. DOI: 10.1016/S0924-2716(02)00114-4.

Leprince, S., Barbot, S., Ayoub, F., \&Avouac, J. P., 2007. Automatic and precise orthorectification, coregistration, and subpixel correlation of satellite images, application to ground deformation measurements. In: IEEE Transactions on Geoscience and Remote Sensing, 45(6), 1529-1558.

Liu, T., Niu, M., \& Yang, Y., 2017. Ice Velocity Variations of the Polar Record Glacier (East Antarctica) Using a RotationInvariant Feature-Tracking Approach. In: Remote Sensing, 10(1), 42. DOI: 10.3390/rs10010042.

Lucchitta, B. K., Mullins, K. F., Allison, A. L., \& Ferrigno, J. G., 1993. Antarctic glacier-tongue velocities from Landsat images: first results. In: Annals of Glaciology, 17, 356-366. 
Pandit, P. H., Jawak, S. D. and Luis, A. J., 2018. 'Estimation of Velocity of the Polar Record Glacier, Antarctica Using Synthetic Aperture Radar (SAR)'. In: Proceedings, 2(7), p. 332. DOI: $10.3390 /$ ecrs-2-05145.

Pandit, P. H., Khot, U., Jawak, S. D., and Luis, A. J., 2018. Spatiotemporal Changes in Velocity of Mellor Glacier, East Antarctica using Landsat-8 data, In: Archives of Photogrammetry, Remote Sensing and Spatial Information Sciences, XLII-5, 787-789. DOI: https://doi.org/10.5194/isprsarchives-XLII-5-787-2018

Reddy, C. D., Sunil, P. S., \& Rao, Y. S., 2008. Velocity of Schirmacher Glacier in East Antarctica from GPS and InSAR, In: Proceedings of the International Workshop on Snow, Ice, Glacier and Avalanches, 108-114, January 7-9, 2008, Mumbai, India.

Ruiz, L., Berthier, E., Masiokas, M., Pitte, P., \&Villalba, R., 2015. First surface velocity maps for glaciers of Monte Tronador, North Patagonian Andes, derived from sequential Pléiades satellite images. In: Journal of Glaciology, 61(229), 908-922. DOI: 10.3189/2015JoG14J134.

Scambos, T. A., Dutkiewicz, M. J., Wilson, J. C., \&Bindschadler, R. A., 1992. Application of image crosscorrelation to the measurement of glacier velocity using satellite image data. In: Remote sensing of environment, 42(3), 177-186. 